\title{
REVIEW
}

\section{Clinical review: mechanical circulatory support for cardiogenic shock complicating acute myocardial infarction}

\author{
Matthew E Cove*1 and Graeme MacLaren ${ }^{1,2}$
}

\begin{abstract}
Acute myocardial infarction is one of the 10 leading reasons for admission to adult critical care units. In-hospital mortality for this condition has remained static in recent years, and this is related primarily to the development of cardiogenic shock. Recent advances in reperfusion therapies have had little impact on the mortality of cardiogenic shock. This may be attributable to the underutilization of life support technology that may assist or completely supplant the patient's own cardiac output until adequate myocardial recovery is established or long-term therapy can be initiated. Clinicians working in the intensive care environment are increasingly likely to be exposed to these technologies. The purpose of this review is to outline the various techniques of mechanical circulatory support and discuss the latest evidence for their use in cardiogenic shock complicating acute myocardial infarction.
\end{abstract}

\section{Introduction}

The in-hospital mortality for acute myocardial infarction (AMI) is currently around 7\% [1]. Death is related predominantly to the development of cardiogenic shock, which affects $5 \%$ to $10 \%$ of all cases of AMI and has a mortality rate of $50 \%$ to $90 \%$ [2,3]. Patients who develop cardiogenic shock frequently require critical care services, and AMI is one of the 10 leading causes for admission to adult critical care units [4]. Over the past three decades, revascularization therapy has revolutionized care for these patients. Recent studies support prompt percutaneous coronary intervention $(\mathrm{PCI})$ when

\footnotetext{
*Correspondence: cove.matthew@gmail.com

'Registrar Intensivist, Cardiothoracic Intensive Care Unit, National University Health System, 5 Lower Kent Ridge Road, Singapore, 119074

Full list of author information is available at the end of the article
}

there is electrocardiographic evidence of an AMI [5], and if PCI is not available within 90 minutes, fibrinolysis should be delivered within 30 minutes [6,7].

Despite these developments, there has been little progress in reducing mortality from cardiogenic shock complicating an AMI [8]. Part of the reason for this is that impaired cardiac contractility may persist many hours after revascularization, an observation described as myocardial stunning [9]. Interventions that can assist or completely supplant the patient's own cardiac output may support these patients until the stunned myocardium recovers (bridge to recovery). Recovery can be predicted using peak serum creatinine kinase levels [10] or contrast echocardiography [11], but even when recovery does not occur, mechanical circulatory support may provide time to determine whether longer-term therapies are appropriate (bridge to decision). In this review, we will outline the various techniques of mechanical circulatory support and discuss the evidence for their use in cardiogenic shock complicating AMI.

\section{Initial management}

Effective treatment of cardiogenic shock begins with early recognition, prompt pharmacological intervention, and appropriate respiratory support. Cardiogenic shock is defined by evidence of tissue hypoperfusion, such as cool peripheries, oliguria, and elevated lactate, in the setting of cardiac dysfunction and adequate filling pressures (Table 1). Hemodynamic criteria include a systolic blood pressure of less than $90 \mathrm{~mm} \mathrm{Hg}$ for more than 30 minutes, a cardiac index of less than $2.2 \mathrm{~L} / \mathrm{min}$ per $\mathrm{m}^{2}$, and a pulmonary artery occlusion pressure of greater than $15 \mathrm{~mm} \mathrm{Hg}$ [12]. An in-depth review of pharmacological and respiratory support for cardiogenic shock is beyond the scope of this article and can be found elsewhere [13]. However, pharmacological interventions predominately involve inotropic support that may perpetuate ischaemia by increasing myocardial oxygen demand. Therefore, mechanical circulatory support should be considered early when inotropes have been initiated. 


\section{Table 1. Cardiogenic shock criteria}

Hemodynamic criteria
Systolic blood pressure (SBP) of less than $90 \mathrm{~mm} \mathrm{Hg}$ for greater than
30 minutes
SBP drop of greater than $30 \mathrm{~mm} \mathrm{Hg}$ below basal for greater than
30 minutes in patients with hypertension
Use of vasopressors and inotropes to keep SBP greater than $90 \mathrm{~mm} \mathrm{Hg}$
Cardiac index of less than $2.2 \mathrm{~L} / \mathrm{min}$ per $\mathrm{m}^{2}$
Pulmonary artery occlusion pressure of greater than $15 \mathrm{~mm} \mathrm{Hg}$
Signs of tissue hypoperfusion
Pale, cool, and clammy peripheries
Prolonged capillary refill times
Altered mental status/confusion
Oliguria
Pulmonary congestion
Tachycardia
Elevated lactate
Mixed venous saturation of less than $65 \%$

\section{Intra-aortic balloon pumps}

Intra-aortic balloon pumps (IABPs) are the most commonly used form of mechanical circulatory support [14]. They were first used in humans in 1968 [15], and percutaneous devices were introduced in 1980 [16]. The device consists of a balloon catheter and a pump console that inflates the balloon with helium. The balloon catheter is placed in the aorta, with the tip just distal to the origin of the left subclavian artery (Figure 1). The balloon is inflated during diastole, displacing aortic blood and augmenting diastolic pressure. Prior to systole, the balloon is deflated, reducing afterload and facilitating left ventricular emptying. In cardiogenic shock, these hemodynamic effects result in reduced myocardial oxygen demand, enhanced coronary blood flow, and increased cardiac output.

Inflation timing is determined using either the electrocardiogram or the arterial pressure waveform. In the latest devices, inflation timing can be controlled with a physiologic timing algorithm that predicts aortic valve closure. When combined with $\mathrm{R}$ wave or pressure predictive deflation, this method maintains balloon synchrony even in patients with severe tachyarrhythmias [17].

As well as providing improved synchrony, modern IABPs have reduced vascular complications. Data from the Benchmark registry, which has collected outcomes for over 37,000 patient episodes [18], demonstrate that smaller ( 8 to 9.5 French) catheter sheaths have reduced the total complication rate to $2.6 \%$ and cut major complications, including limb, bowel, and renal ischemia, to under $0.5 \%$. As a result, mortality directly attributable to IABP use is currently less than $0.05 \%$ [19]. Owing to a

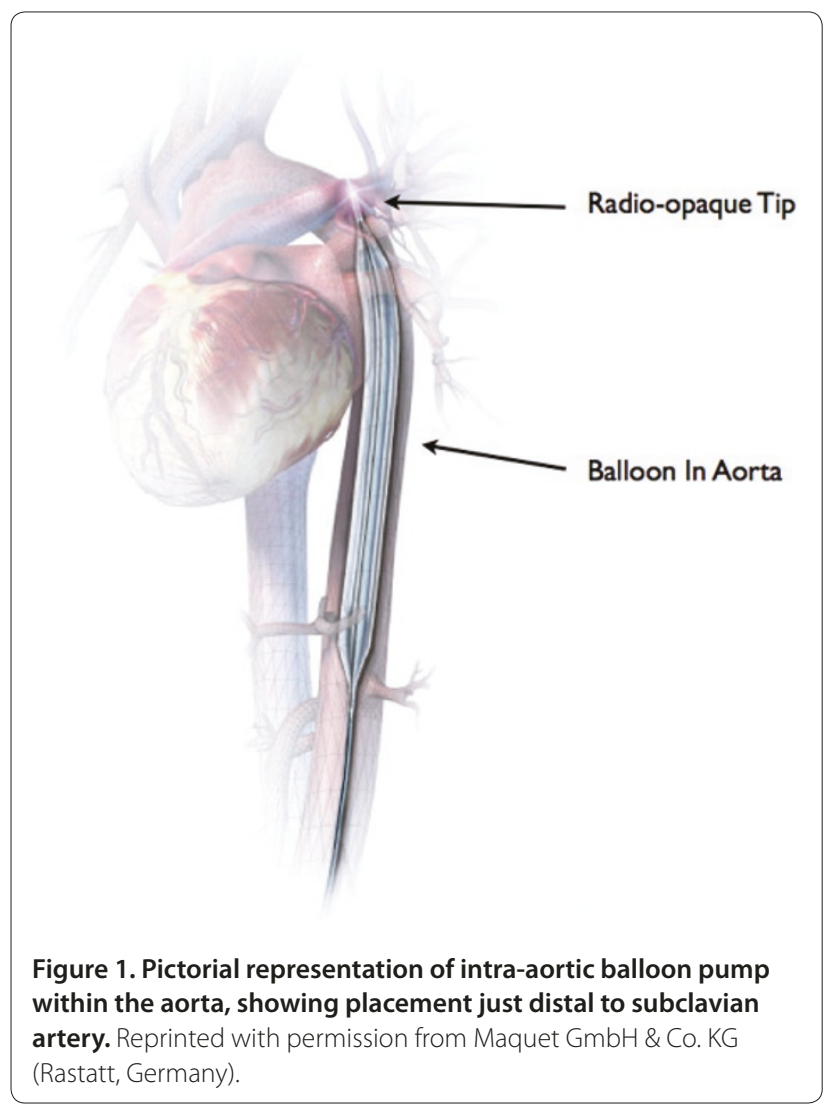

higher risk of limb ischemia, these devices, even with smaller catheters, should be used cautiously in patients with severe peripheral vascular disease. IABPs are not suitable for all patients and are specifically contraindicated in those with severe aortic regurgitation, aortic dissection, or large aneurysms.

\section{Clinical evidence supporting intra-aortic balloon pump in cardiogenic shock}

Attempts to study IABP use in cardiogenic shock have been affected by poor recruitment. This may reflect the difficulty of obtaining timely consent and randomization in the critically ill. For example, the SMASH (Swiss Multicenter Evaluation of Early Angioplasty for Shock Following Myocardial Infarction) study was stopped after recruiting only 55 patients during a 4-year period [20]. Similarly, the TACTICS (Thrombolysis and Counterpulsation to Improve Survival in Myocardial Infarction Complicated by Hypotension and Suspected Cardiogenic Shock) trial was stopped after 3 years when only 57 out of a planned 538 patients were randomly assigned [21].

Early experiences using IABPs in the treatment of cardiogenic shock secondary to AMI were disappointing. Two studies published prior to the availability of reperfusion therapy reported no benefit (Table 2) [22,23]. This is not surprising since patients who develop 
Table 2. Mortality evidence supporting intra-aortic balloon pump use in cardiogenic shock complicating an acute myocardial infarction

\begin{tabular}{|c|c|c|c|c|}
\hline Study & Patients & IABPa & No IABPa & $P$ value \\
\hline \multicolumn{5}{|l|}{ Pre-thrombolysis } \\
\hline O'Rourke et al. [22] (1981) & 30 & $50 \%$ & $43 \%$ & 0.09 \\
\hline Flaherty et al. [23] (1985) & 20 & $52 \%$ & $53 \%$ & - \\
\hline \multicolumn{5}{|l|}{ Thrombolysis era } \\
\hline Kovack et al. [25] (1997) & 335 & $93 \%$ & $37 \%$ & 0.0002 \\
\hline GUSTO-I [26] (1997) & 310 & $47 \%^{\mathrm{b}}$ & $60 \%{ }^{b}$ & 0.06 \\
\hline SHOCK [27] (2000) & 856 & $47 \%$ & $63 \%$ & 0.007 \\
\hline NRMI-2 [28] (2001) & $12,054^{c}$ & $49 \%$ & $67 \%$ & - \\
\hline \multicolumn{5}{|l|}{ Reperfusion by PCl } \\
\hline NRMI-2 [28] (2001) & $7,881^{\mathrm{C}}$ & $47 \%$ & $42 \%$ & - \\
\hline
\end{tabular}

an-hospital mortality expressed as a percentage. ${ }^{\mathrm{b} T h i r t y-d a y ~ m o r t a l i t y . ~ T o t a l ~ n u m b e r ~ o f ~ p a t i e n t s ~ i n ~ t h e ~ s t u d y, ~ i n c l u d i n g ~ t h o s e ~ w i t h ~ n o ~ r e p e r f u s i o n ~ t h e r a p y, ~ w a s ~} 23,180$. GUSTO-I, Global Utilization of Streptokinase and Tissue Plasminogen Activator for Occluded Coronary Arteries; IABP, intra-aortic balloon pump; NRMI-2, National Registry of Myocardial Infarction 2; PCI, percutaneous coronary intervention; SHOCK, Should We Emergently Revascularize Occluded Coronary Arteries for Cardiogenic Shock.

cardiogenic shock have typically infarcted greater than $40 \%$ of their left ventricle [24]. It is therefore unlikely that IABP support would be successful without definitive reperfusion therapy.

In 1997, Kovack and colleagues [25] demonstrated that patients who developed cardiogenic shock complicating an AMI were twice as likely to survive when an IABP was used in conjunction with pharmocological reperfusion strategies (Table 2). In the same year, the GUSTO-I (Global Utilization of Streptokinase and Tissue Plasminogen Activator for Occluded Coronary Arteries) trial reported that early IABP use was associated with a trend toward lower 30 -day (47\% versus $60 \% ; P=0.06$ ) and 1 -year (57\% versus 67\%; $P=0.04$ ) mortality rates in patients who presented with cardiogenic shock complicating an AMI [26]. Analysis of the larger SHOCK (Should We Emergently Revascularize Occluded Coronary Arteries for Cardiogenic Shock) trial (1,190 patients) confirmed this benefit, demonstrating statistically significant lower in-hospital mortality for cardiogenic shock patients who received IABP verses those who did not (50\% versus $72 \%$; $P \leq 0.0001$ ) [27]. However, a significant confounding factor in these studies was a higher number of revascularization procedures in the IABP group.

To eliminate confounding, the SHOCK data were reevaluated comparing IABP plus fibrinolysis with fibrinolysis alone. In this analysis, in-hospital mortality was still improved by $25 \%$ (47\% versus $63 \% ; P=0.007$ ) [27]. A similar benefit was observed in the larger National Registry of Myocardial Infarction 2 (NRMI-2) ( $\mathrm{n}=23,180$ patients), in which the use of IABP as an adjunct to fibrinolysis, in cardiogenic shock, reduced in-hospital odds of death by $18 \%$ (odds ratio (OR) 0.82, 95\% confidence interval (CI) 0.72 to 0.93 ) [28]. A recent meta-analysis by Sjauw and colleagues [29] demonstrated that this benefit remains statistically significant beyond the in-hospital period, with an absolute decrease in 30 -day mortality of $18 \%$ (95\% CI $16 \%$ to $20 \%$; $P<0.0001)$.

IABP benefits are less clear for cardiogenic shock patients who undergo primary PCI. In the SHOCK trial, revascularization with $\mathrm{PCI}$ resulted in a significant reduction of mortality when compared with medical therapy, including fibrinolysis. Importantly, IABP use was $86 \%$ in both groups, and mortality in the medical therapy group was lower than expected [8]. This suggests that IABP plus medical therapy may result in lower mortality and that IABP plus PCI further improves mortality. In contrast, the NRMI-2 study observed that IABP as an adjunct to primary PCI resulted in a higher mortality (OR 1.27, 95\% CI 1.07 to 1.50) in patients with cardiogenic shock complicating an AMI [28]. This negative association is also evident in the recent metaanalysis by Sjauw and colleagues [29]. However, for this part of their analysis, only two registries were used: the NRMI-2 study and the data of Sjauw and colleagues. In the absence of randomization, the trend may be confounded since patients receiving both PCI and an IABP in the NRMI-2 study were more likely to have cardiogenic shock complicated by previous PCI (OR 1.85, CI 1.64 to 2.09) and experience an inter-hospital transfer (OR 2.57, CI 2.40 to 2.75) [28].

A more recent study that randomly assigned patients with AMI complicated by cardiogenic shock to either IABP plus PCI or PCI alone did not demonstrate significant improvement in APACHE II (Acute Physiology and Chronic Health Evaluation II) scores or mortality over the first 4 days of admission (36.8\% in the IABP group versus 28.6\%) [30]. However, this study was 


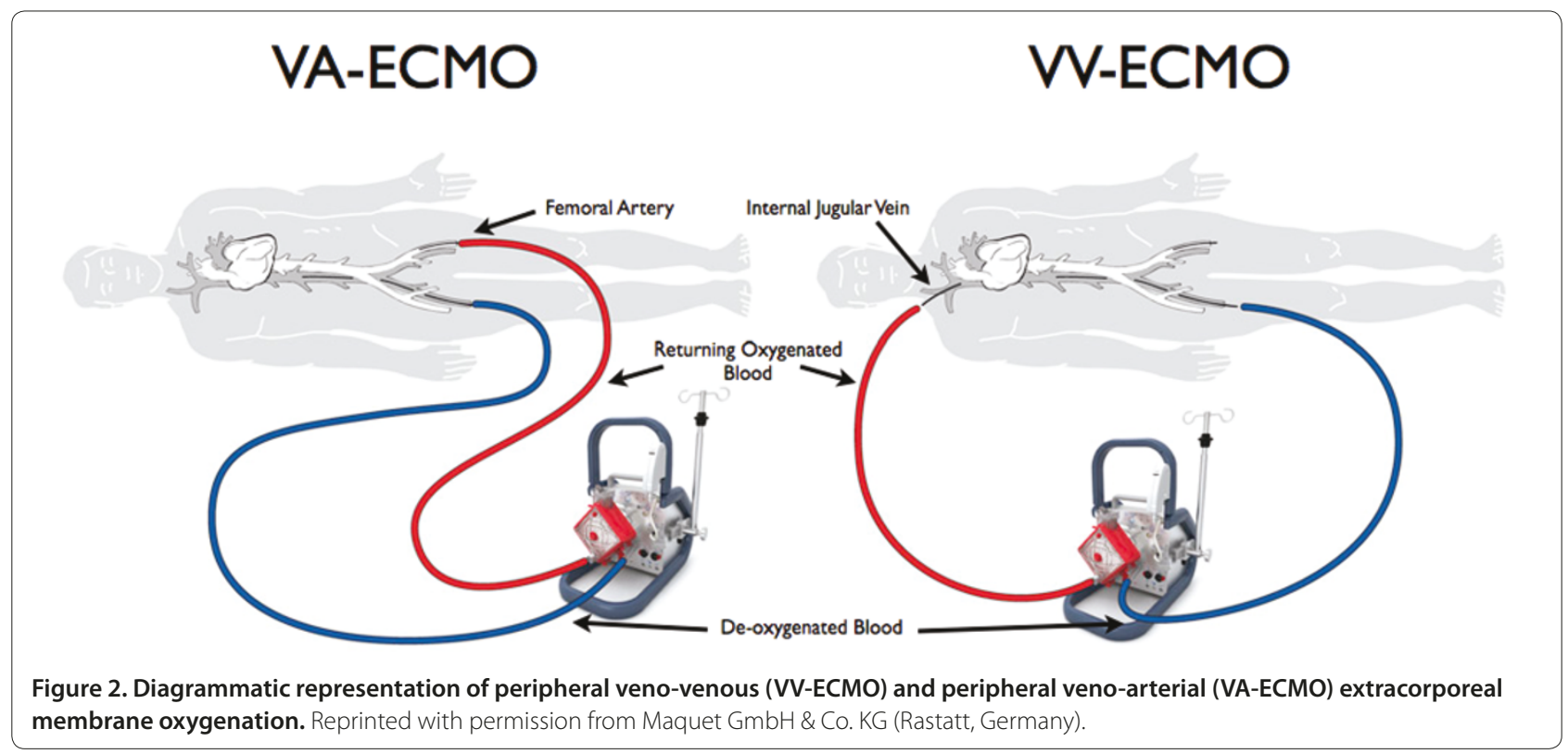

not powered to assess mortality. Large randomized clinical trials are required to resolve this issue and address whether the current American Heart Association and American College of Cardiology guidelines recommending PCI and IABP in the setting of cardiogenic shock complicating AMI require revision [31]. In the meantime, we recommend IABP use in any patient meeting the criteria for cardiogenic shock in the setting of an AMI when inotrope therapy has been initiated, whether the patient has received PCI or thrombolysis or neither. IABPs are more widely available than more complex forms of mechanical circulatory support, have a low complication rate, and decrease myocardial oxygen demand. IABPs should be routinely available at centers treating patients with AMI.

\section{Extracorporeal membrane oxygenation}

When there is evidence of inadequate tissue oxygen delivery despite IABP, invasive ventilation, and inotropes, full circulatory support should be considered. Extracorporeal membrane oxygenation (ECMO) can subsume the function of both heart and lungs and was first successfully used in adults in 1972 [32]. De-oxygenated blood is removed from the body, pumped through an artificial oxygenator, and returned to the circulation. Modern oxygenators consist of multiple, small hollow fibers lined with polymethylpentene and allow gas but not liquid transfer. Oxygen and carbon dioxide exchange is achieved as blood runs through the center of the fibers and an oxygen/air mix flows on the outside. Blood flow is generated by a centrifugal pump, where a rotating impeller spins blood outwards, creating centrifugal acceleration. Since no compression is involved, high flow rates can be generated with minimal trauma to blood components.

ECMO can be broadly categorized into two types: veno-venous ECMO (VV-ECMO) and veno-arterial ECMO (VA-ECMO) (Figure 2). The type selected depends on therapeutic goals. VV-ECMO is appropriate only for respiratory failure. VA-ECMO is used for cardiogenic shock and is currently the fastest growing indication for ECMO worldwide [33]. In adults, blood is usually removed through a femoral vein and returned through a femoral artery (peripheral ECMO). Occasionally, other cannulation strategies, such as directly cannulating the right atrium and aorta (central ECMO), may be employed.

Peripheral ECMO is less invasive, is easier to place, and can be placed percutaneously by surgeons or intensivists. It can be initiated quickly, making it more appropriate in emergencies. However, the cardiac output of the failing heart competes with retrograde ECMO flow from the femoral aortic cannula, producing admixing in the thoracic aorta and an increase in left ventricular wall tension. If there is concomitant respiratory failure, this can result in the delivery of inadequately oxygenated blood to the coronary and cerebral circulations and hinder recovery [34]. Central ECMO is not associated with this problem but is slower to initiate and may have a higher complication rate with bleeding and infection. It is usually confined to the support of patients after surgical revascularization. Peripheral VA-ECMO is adequate for most forms of cardiogenic shock, but frequent echocardiography is necessary to monitor for progressive ventricular dilatation. If this develops, the left atrium can be vented either by changing the ECMO circuit 
configuration or by performing a percutaneous atrial septostomy [35-37].

VA-ECMO is associated with bleeding in $30 \%$ to $60 \%$ of cases $[38,39]$, sometimes requiring massive transfusions. New pumps and improved circuit biocompatibility allow lower levels of anticoagulation to be used and should reduce the impact of this complication. Clotting abnormalities predispose to hemorrhagic stroke, which, combined with circuit embolic complications such as air bubbles or clots, results in an overall stroke rate of $3 \%$ to $12 \%$ $[33,40,41]$. Other complications include nosocomial infection in $50 \%$ to $60 \%$ [40,41] and multi-organ dysfunction in 33\% [39], although the contribution of ECMO is not easy to separate from the complications of severe critical illness. Device and circuit complications appear to be declining [33].

\section{Evidence supporting extracorporeal membrane oxygenation in cardiogenic shock complicating acute myocardial infarction}

In 1992, the Cleveland Clinic reported their experience with adult ECMO in postcardiotomy patients, of whom $25.3 \%$ survived to discharge (Table 3) [42]. Two years later, this improved to $30.4 \%$ [43]. In 1999, Pittsburgh's Allegheny Hospital reported ECMO use in high-risk patients undergoing PCI, of whom $85 \%$ survived to hospital discharge [44]. In 2008, two studies from Europe (Formica and colleagues [39] and Combes and colleagues [38]) demonstrated survival to discharge rates of $28 \%$ to $31 \%$ when ECMO was used for postcardiotomy cardiogenic shock or cardiogenic shock complicating AMI (Table 3). Patients were selected for ECMO if they failed conventional treatment, including inotropes, ventilation, or IABP. PCI was frequently used in the AMI patients.

The variable survival rates reflect that fact these are small single-center studies. The Extracorporeal Life Support Organization (ELSO) registry addresses this limitation by recording the experience of over 170 ECMO centers worldwide. ELSO has accumulated data on over 40,000 ECMO cases, of whom approximately 3,000 are adults. In 2009, ELSO reported a survival rate of $39 \%$ for adult cardiogenic shock [33].

The timing of ECMO is controversial, given the absence of guidelines. We recommend considering this therapy in patients with ongoing tissue hypoperfusion despite escalating inotropes, appropriate ventilatory support, and initiation of IABP. Evidence of tissue hypoperfusion includes worsening organ dysfunction, rising lactate, or falling central venous oxygen saturation. Inotrope scores $[45,46]$ approaching 40 to 50 also indicate that mechanical circulatory support may be required (Figure 3). Additional considerations include the rate of decompensation as well as local resources (for example, how quickly ECMO can be initiated or whether the patient has to be
Table 3. Evidence supporting extracorporeal membrane oxygenation use in cardiogenic shock complicating an acute myocardial infarction

\begin{tabular}{lccc}
\hline Study & Patients & $\begin{array}{c}\text { Survival } \\
\text { rate }^{\text {a }}\end{array}$ & $\begin{array}{c}\text { Cardiogenic shock } \\
\text { etiology }\end{array}$ \\
\hline Golding et al. [42] (1992) & 91 & $25.3 \%$ & Post-CABG $^{\text {b }}$ \\
Muehrcke et al. [43] (1996) & 23 & $30.4 \%$ & Post-CABG $^{\text {b }}$ \\
Magovern et al. [44] (1999) & 27 & $85 \%$ & UA or CHF \\
Formica et al. [39] (2008) & 18 & $27.8 \%$ & AMl/Post-CABG \\
Combes et al. [38] (2008) & 16 & $31.3 \%$ & AMl \\
ELSO [33] (2009) & $153^{c}$ & $39 \%$ & Not defined \\
\hline
\end{tabular}

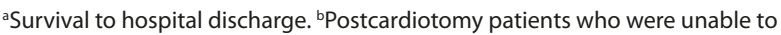
wean off bypass or developed postoperative cardiogenic shock. 'Number of extracorporeal membrane oxygenation runs. AMI, acute myocardial infarction; CABG, coronary artery bypass graft; CHF, congestive heart failure; ELSO, Extracorporeal Life Support Organization; UA, unstable angina.

transferred). Delaying ECMO until the inotrope score is 60 may be associated with poorer outcomes [46].

Candidates should be selected only if significant organ recovery is expected and there is no contraindication to long-term mechanical support or transplant (Table 4). Up to $60 \%$ of survivors cannot be weaned and require a ventricular assist device (VAD) or transplantation [38,41]. ECMO may therefore provide a bridge to decision; it is less costly than VADs, can be initiated quickly, and offers biventricular and respiratory support, thereby stabilizing patients while their suitability for a VAD or transplant is evaluated [47]. Institutions that do not provide this therapy should consider referring patients to an experienced center once IABP support has been initiated. In these situations, expert retrieval teams from the specialist center should provide transport $[48,49]$.

\section{Ventricular assist devices}

VADs were first used successfully in humans in 1966 [50]. Three types are used: left ventricular assist (LVAD), right ventricular assist, or biventriciular assist (BiVAD) device. LVAD is the one most commonly used in cardiogenic shock complicating an AMI. Blood is removed from a cannula in the left atrium, or apex of the left ventricle, and pumped into the ascending aorta. Depending on the pump, flow will be pulsatile or continuous. In pulsatile pumps, also known as first-generation VADs, blood fills a compliant, collapsible chamber that is intermittently compressed. Continuous flow pumps use an internal rotating impeller and these newer devices are referred to as second-generation pumps. They may be centrifugal (see 'Extracorporeal membrane oxygenation' section above) or axial, where the impeller is cylindrical with helical blades, similar to an Archimedes' screw. The latest devices, third-generation VADs, spin and levitate the impeller within an electromagnetic field, reducing blood trauma and prolonging serviceable life [51]. A range of 


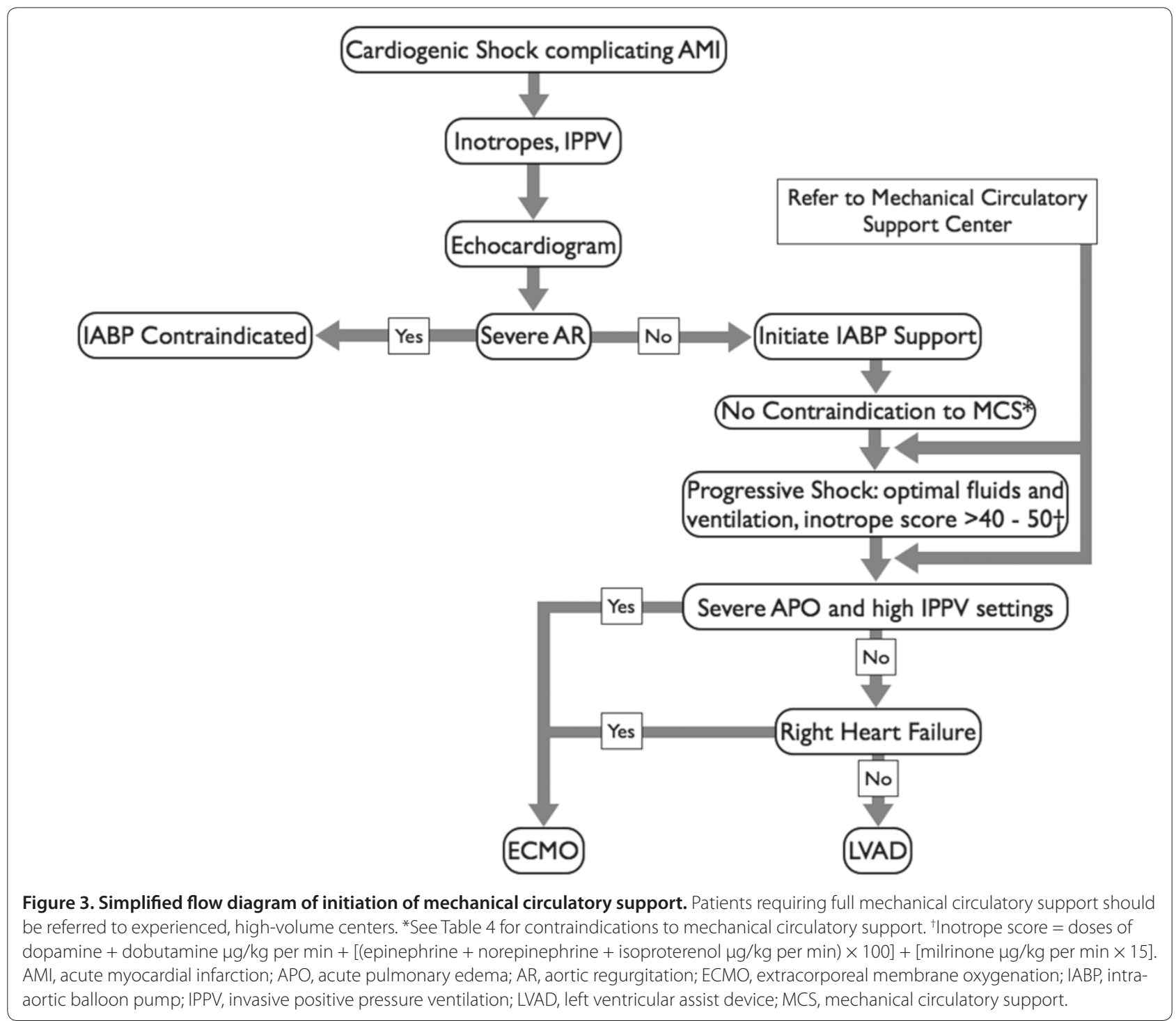

LVADs are available and can be broadly distinguished by whether cannulation is achieved percutaneously or centrally via a surgical sternotomy (Table 5).

\section{Percutaneous left ventricular assist device}

In acute cardiogenic shock complicating an MI, percutaneous LVADs (pLVADs) hold the most promise. They can be initiated quickly and do not require a sternotomy. The two most studied devices are the TandemHeart (CardiacAssist, Inc., Pittsburgh, PA, USA) and Impella (Abiomed, Aachen, Germany).

The TandemHeart removes blood from the left atrium by means of a catheter that is transeptally placed in the left atrium via a femoral vein and returns it to the circulation through a femoral artery by means of a centrifugal pump (Figure 4). This device has been compared with an IABP (Table 6). In one study, 41 patients presenting with cardiogenic shock following an AMI were randomly assigned to receive an IABP or the TandemHeart prior to PCI. The TandemHeart resulted in a larger improvement in the cardiac power index compared with IABP $(0.37$ versus $0.28, P=0.004)$ but did not translate into improved 30-day mortality (IABP $45 \%$ versus VAD $43 \%, P=0.86$ ) [52]. In another study, 30 patients presenting with cardiogenic shock were randomly assigned, and $70 \%$ of them had cardiogenic shock secondary to an AMI. In that study, the TandemHeart also improved hemodynamics more than the IABP did ( $\Delta$ cardiac output $1.2 \mathrm{~L} / \mathrm{min}$ versus $0.6 \mathrm{~L} / \mathrm{min}, P<0.05$ ) [53]. Again, this did not confer a significant 30-day survival advantage (53\% survival for TandemHeart versus $64 \%$ for IABP). However, in both of these studies, a larger number of hemorrhagic complications and ischemic limbs were seen in the TandemHeart groups. 


\section{Table 4. Contraindications to full mechanical circulatory support}

Prolonged cardiopulmonary resuscitation with inadequate perfusion

Advanced age

Advanced malignancy

Existing organ dysfunction

Advanced chronic obstructive pulmonary disease

Interstitial lung disease

Liver cirrhosis

Previous stroke with significant disability

Dementia

End-stage renal failure (relative)

Contraindication to anticoagulation (relative)

Contraindication to transplant (relative)

The Impella percutaneous pump has been recently studied under conditions similar to those of the TandemHeart. Impella uses an axial pump that is placed across the aortic valve via one of the femoral arteries (Figure 5). In 2008, the ISAR-SHOCK study (Impella LP2.5 versus IABP in Cardiogenic SHOCK) randomly assigned 25 patients with cardiogenic shock following an AMI to receive the Impella or an IABP. Investigators found that the cardiac index after 30 minutes of support was significantly increased in patients with the Impella LP2.5 compared with patients with IABP (Impella: $\Delta$ cardiac index $=0.49 \pm 0.46 \mathrm{~L} / \mathrm{min}$ per $\mathrm{m}^{2}$; IABP: $\Delta$ cardiac index $=0.11 \pm 0.31 \mathrm{~L} / \mathrm{min}$ per $\mathrm{m}^{2} ; P=0.02$ ) [54]. The mortality rate was $43 \%$ for both groups, and of particular note, there was no difference in major bleeding or distal limb ischemia between the two groups.

When these three studies are combined in a metaanalysis, it is still not possible to detect a mortality benefit

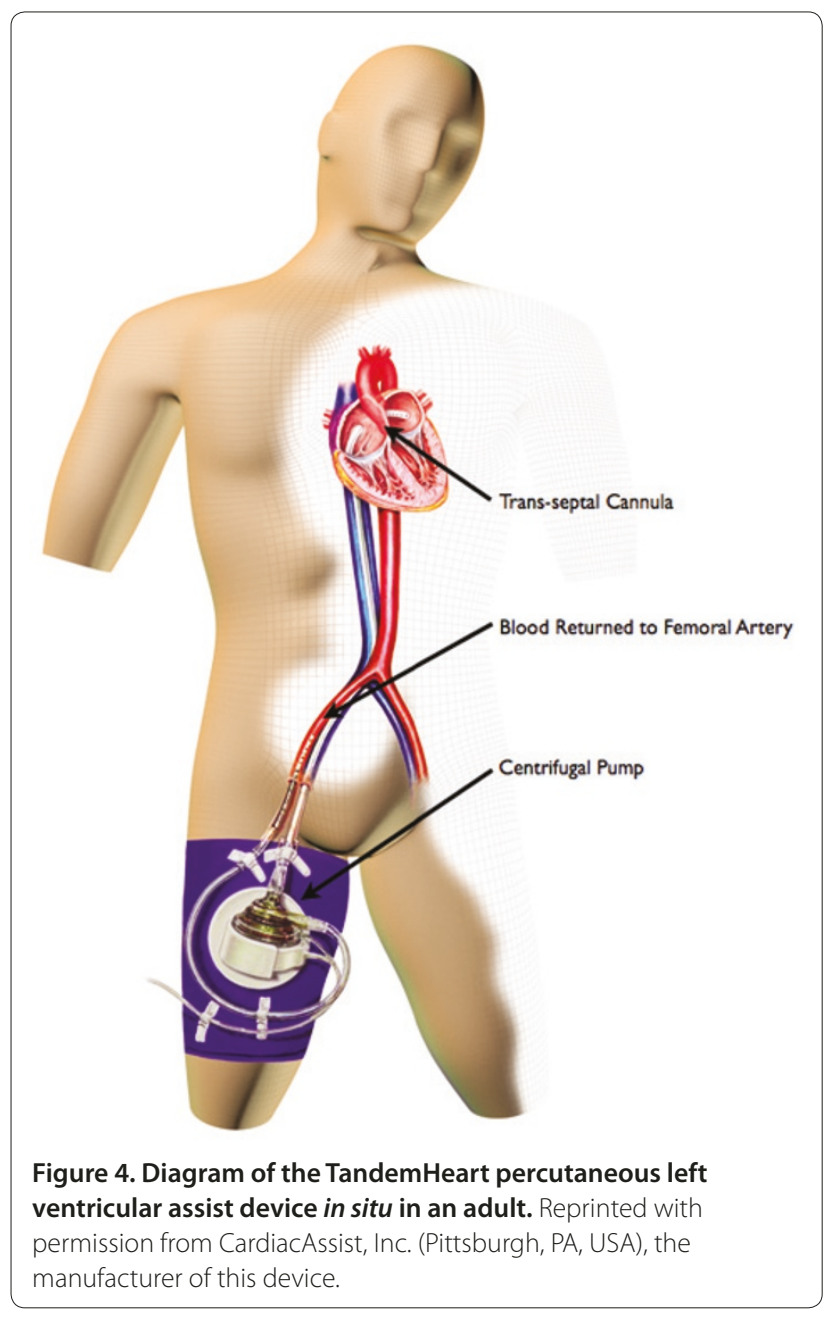

[55]. However, it is arguable that an overall number of 100 patients is still too small. In addition to offering no clear survival benefits, pLVADs provide only left

Table 5. Classification of ventricular assist devices

\begin{tabular}{|c|c|c|c|}
\hline Access & Ventricular support & Abbreviation & Examples $^{\mathrm{a}}$ \\
\hline \multirow[t]{3}{*}{ Percutaneous } & Left & pLVAD & TandemHeart (CardiacAssist, Inc., Pittsburgh, PA, USA) \\
\hline & & & Impella 2.5L (Abiomed, Aachen, Germany) \\
\hline & & & Impella 5L (Abiomed) \\
\hline \multicolumn{4}{|l|}{ Surgical } \\
\hline \multirow[t]{3}{*}{ Extracorporeal } & Right/Left/Biventricular & RVAD/LVAD/BiVAD & CentriMag (Levitronix LLC, Waltham, MA, USA) \\
\hline & & & Bio-Medicus (Eden Prairie, MN, USA) \\
\hline & & & DeltaStream (Medos Medizintechnik AG, Stolberg, Germany) \\
\hline \multirow[t]{3}{*}{ Implantable } & Left & LVAD & HeartMate II (Thoratec Corporation, Pleasanton, CA, USA) \\
\hline & & & $\begin{array}{l}\text { Jarvik } 2000 \text { (Jarvik Heart Inc., New York, NY) and Incor } \\
\text { (Berlin Heart AG, Berlin, Germany) }\end{array}$ \\
\hline & & & $\begin{array}{l}\text { HeartAssist } 5 \text { (MicroMed Cardiovascular, Inc., Houston, TX, USA) } \\
\text { and DuraHeart (Terumo Heart Inc., Ann Arbor, MI, USA) }\end{array}$ \\
\hline
\end{tabular}

aThis list is not exhaustive and includes only a few continuous flow devices. BiVAD, biventricular assist device; LVAD, left ventricular assist device; pLVAD, percutaneous left ventricular assist device; RVAD, right ventricular assist device. 
Table 6. Comparative data of studies into ventricular assist device use in cardiogenic shock complicating an acute myocardial infarction.

\begin{tabular}{|c|c|c|c|c|c|c|}
\hline \multirow[b]{2}{*}{ Study } & \multirow[b]{2}{*}{ Patients } & \multicolumn{3}{|c|}{$\Delta$ Cardiac output, L/min } & \multicolumn{2}{|c|}{ 30-day survival, percentage } \\
\hline & & VAD & IABP & $P$ value & VAD & IABP \\
\hline \multicolumn{7}{|l|}{ TandemHeart (pLVAD) } \\
\hline Thiele et al. [52] (2005) & 41 & 1.0 & 0.3 & 0.007 & 57 & 55 \\
\hline Burkhoff et al. [53] (2006) & 42 & 1.2 & 0.6 & - & 53 & 64 \\
\hline \multicolumn{7}{|l|}{ Impella (pLVAD) } \\
\hline Seyfarth et al. [54] (2008) & 25 & 0.5 & 0.1 & 0.18 & 54 & 54 \\
\hline \multicolumn{7}{|l|}{ Centrimag (eBiVAD) } \\
\hline John et al. [61] (2007) & 12 & \multicolumn{3}{|c|}{ Titrated for cardiac index $>2.2 \mathrm{~L} / \mathrm{min}$ per $\mathrm{m}^{2}$} & 75 & N/A \\
\hline
\end{tabular}

eBiVAD, extracorporeal biventricular assist device; IABP, intra-aortic balloon pump; N/A, not applicable; pLVAD, percutaneous left ventricular assist device; VAD, ventricular assist device.

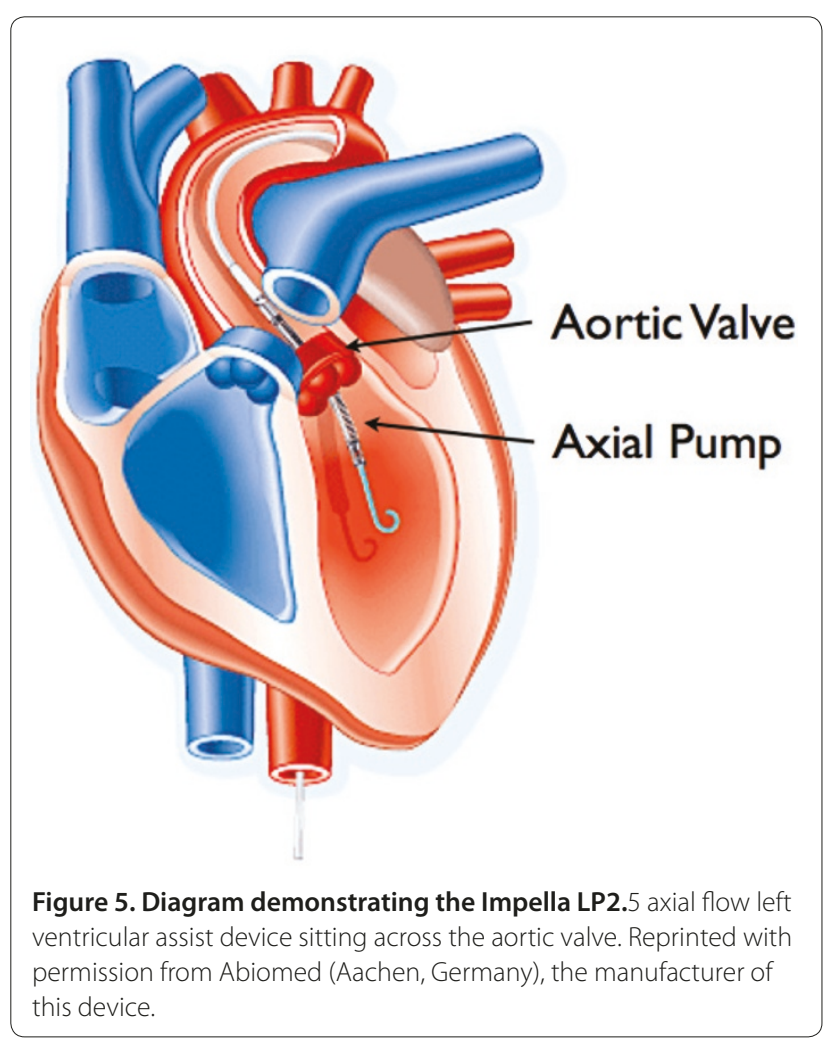

ventricular support. Thus, they are inappropriate for cardiogenic shock due to right ventricular ischemia, and although successful cases of percutaneous right ventricular assist [56,57] and even biventricular assist [58] have been reported, they required substantial modification of existing technology. Despite this, the improved hemodynamics are impressive and percutaneous devices are set to become increasingly important in the management of acute cardiogenic shock $[59,60]$, especially if larger studies demonstrate that these hemodynamic benefits translate into significant survival benefits.

\section{Surgically placed ventricular assist device (extracorporeal and implantable)}

In the acute setting of cardiogenic shock complicating AMI, surgical VAD placement has proven to be challenging. The additional trauma of surgery compounds the multi-organ dysfunction and coagulopathy associated with extracorporeal circuits. However, thirdgeneration pumps have been successfully surgically placed in the acute setting by means of cannulas tunneled through the chest wall. In one study, the Centrimag (Levitronix LLC, Waltham, MA, USA) was used to provide temporary BiVAD for 12 patients presenting with refractory shock following AMI. Eight patients were successfully bridged to an implantable VAD, and two patients recovered allowing device explantation. Overall 1-year survival was $62.5 \%$ [61].

Implantable VADs allow patients to be discharged home, providing a bridge to transplant, bridge to recovery, or destination therapy. Destination therapy is particularly attractive since transplant demand greatly exceeds donor availability. Studies in the last decade have demonstrated that implantable pulsatile LVADs are superior to medical therapy in end-stage heart failure patients who are ineligible for a transplant [62,63]. Recently, it was demonstrated that third-generation devices result in decreased mortality and greater reliability when compared with pulsatile LVADs [64].

VADs are susceptible to complications similar to those experienced with ECMO. Neurological insults affect $4 \%$ to $12 \%$ of patients, infection $20 \%$ to $30 \%$, and bleeding $30 \%$ to $40 \%[52,53,65]$. Device malfunction rates are improving; over a 2 -year period, less than $10 \%$ of implantable thirdgeneration pumps require replacement [64].

The decision to initiate VAD therapy should be made under the same circumstances as those described above for ECMO. The precise modality chosen depends on institutional experience and patient factors. For isolated left ventricular failure, with minimal respiratory 
disturbance, a pLVAD may be sufficient. Where there is concomitant respiratory failure or high ventilatory settings or when biventricular support is desired through a percutaneous approach, ECMO is more appropriate (Figure 3). Occasionally, the two may be used together [66]. In patients between these extremes, the factors of institutional experience, likelihood of recovery, and whether surgical revascularization is required will dictate choice. Finally, pursuing this technology is not without controversy in terms of resource allocation and ethics [67]. These issues vary substantially depending on healthcare infrastructure, financing sources, and donor (as well as blood product) availability.

\section{Conclusions}

When cardiogenic shock complicating AMI is refractory to medical therapy, the only options available for survival are mechanical support strategies. Mechanical support can be applied in a stepwise progression starting with IABP support, followed by either ECMO or an LVAD. In the acute setting, these devices may provide circulatory support until the benefits of revascularization are realized. In the event that weaning is not possible, these devices serve as a bridge to decision or transplant. In patients who are ineligible for transplant, implantable VADs hold the promise of viable destination therapy.

\section{Abbreviations}

AMI, acute myocardial infarction; BiVAD, biventricular assist device; $\mathrm{Cl}$, confidence interval; ECMO, extracorporeal membrane oxygenation; ELSO, Extracorporeal Life Support Organization; IABP, intra-aortic balloon pump; LVAD, left ventricular assist device; NRMI-2, National Registry of Myocardial Infarction 2; OR, odds ratio; $\mathrm{PCl}$, percutaneous coronary intervention; PLVAD, percutaneous left ventricular assist device; SHOCK, Should We Emergently Revascularize Occluded Coronary Arteries for Cardiogenic Shock; VAD, ventricular assist device; VA-ECMO, veno-arterial extracorporeal membrane oxygenation; $\mathrm{V}$-ECMO, veno-venous extracorporeal membrane oxygenation.

\section{Competing interests}

The authors declare that they have no competing interests.

\section{Authors' contributions}

MEC contributed to the writing and editing of the text and produced the figures and tables. GM contributed to the writing and editing of the text. Both authors read and approved the final manuscript.

\section{Author details}

'Cardiothoracic Intensive Care Unit, National University Health System, 5 Lower Kent Ridge Road, Singapore, 119074. Paediatric Intensive Care Unit, Royal Children's Hospital, Melbourne, Australia.

Published: 14 October 2010

\section{References}

1. Steg PG, Goldberg RJ, Gore JM, Fox KA, Eagle KA, Flather MD, Sadiq I, Kasper R, Rushton-Mellor SK, Anderson FA: Baseline characteristics, management practices, and in-hospital outcomes of patients hospitalized with acute coronary syndromes in the Global Registry of Acute Coronary Events (GRACE). Am J Cardio/ 2002, 90:358-363.

2. Lindholm MG, Kober L, Boesgaard S, Torp-Pedersen C, Aldershvile J: Cardiogenic shock complicating acute myocardial infarction; prognostic impact of early and late shock development. Eur Heart J 2003, 24:258-265.
3. Ryan TJ: Early revascularization in cardiogenic shock--a positive view of a negative trial. N Engl J Med 1999, 341:687-688.

4. Harrison DA, Brady AR, Rowan K: Case mix, outcome and length of stay for admissions to adult, general critical care units in England, Wales and Northern Ireland: the Intensive Care National Audit \& Research Centre Case Mix Programme Database. Crit Care 2004, 8:R99-111.

5. Rathore SS, Curtis JP, Chen J, Wang Y, Nallamothu BK, Epstein AJ, Krumholz HM: Association of door-to-balloon time and mortality in patients admitted to hospital with ST elevation myocardial infarction: national cohort study. BMJ 2009, 338:b1807.

6. Antman EM, Hand M, Armstrong PW, Bates ER, Green LA, Halasyamani LK, Hochman JS, Krumholz HM, Lamas GA, Mullany CJ, Pearle DL, Sloan MA, Smith SC Jr.; 2004 Writing Committee Members, Anbe DT, Kushner FG, Ornato JP, Jacobs AK, Adams CD, Anderson JL, Buller CE, Creager MA, Ettinger SM, Halperin JL, Hunt SA, Lytle BW, Nishimura R, Page RL, Riegel B, Tarkington LG, Yancy CW: 2007 Focused Update of the ACC/AHA 2004 Guidelines for the Management of Patients With ST-Elevation Myocardial Infarction: a report of the American College of Cardiology/American Heart Association Task Force on Practice Guidelines: developed in collaboration With the Canadian Cardiovascular Society endorsed by the American Academy of Family Physicians: 2007 Writing Group to Review New Evidence and Update the ACC/AHA 2004 Guidelines for the Management of Patients With ST-Elevation Myocardial Infarction, Writing on Behalf of the 2004 Writing Committee. Circulation 2008, 117:296-329.

7. Kushner FG, Hand M, Smith SC Jr., King SB 3rd, Anderson JL, Antman EM, Bailey SR, Bates ER, Blankenship JC, Casey DE Jr., Green LA, Hochman JS, Jacobs AK, Krumholz HM, Morrison DA, Ornato JP, Pearle DL, Peterson ED, Sloan MA, Whitlow PL, Williams DO; American College of Cardiology Foundation/American Heart Association Task Force on Practice Guidelines: 2009 Focused Updates: ACC/AHA Guidelines for the Management of Patients With ST-Elevation Myocardial Infarction (updating the 2004 Guideline and 2007 Focused Update) and ACC/AHA/SCAI Guidelines on Percutaneous Coronary Intervention (updating the 2005 Guideline and 2007 Focused Update): a report of the American College of Cardiology Foundation/American Heart Association Task Force on Practice Guidelines. Circulation 2009, 120:2271-2306.

8. Hochman JS, Sleeper LA, Webb JG, Sanborn TA, White HD, Talley JD, Buller CE, Jacobs AK, Slater JN, Col J, McKinlay SM, LeJemtel TH: Early revascularization in acute myocardial infarction complicated by cardiogenic shock. SHOCK Investigators. Should We Emergently Revascularize Occluded Coronaries for Cardiogenic Shock. N Engl J Med 1999, 341:625-634.

9. Camici PG, Prasad SK, Rimoldi OE: Stunning, hibernation, and assessment of myocardial viability. Circulation 2008, 117:103-114.

10. Solomon SD, Glynn RJ, Greaves S, Ajani U, Rouleau JL, Menapace F, Arnold JM, Hennekens C, Pfeffer MA: Recovery of ventricular function after myocardial infarction in the reperfusion era: the healing and early afterload reducing therapy study. Ann Intern Med 2001, 134:451-458.

11. Swinburn JM, Lahiri A, Senior R: Intravenous myocardial contrast echocardiography predicts recovery of dysynergic myocardium early after acute myocardial infarction. J Am Coll Cardiol 2001, 38:19-25.

12. Hollenberg SM, Kavinsky CJ, Parrillo JE: Cardiogenic shock. Ann Intern Med 1999, 131:47-59.

13. Allen LA, O'Connor CM: Management of acute decompensated heart failure. CMAJ 2007, 176:797-805.

14. Kantrowitz A: Origins of Intraaortic ballon pumping. Ann Thorac Surg 1990, 50:672.

15. Kantrowitz A, Tjonneland S, Freed PS, Phillips SJ, Butner AN, Sherman JL Jr.: Initial clinical experience with intraaortic balloon pumping in cardiogenic shock. JAMA 1968, 203:113-118.

16. Bregman D, Nichols AB, Weiss MB, Powers ER, Martin EC, Casarella WJ: Percutaneous intraaortic balloon insertion. Am J Cardiol 1980, 46:261-264.

17. Schreuder JJ, Castiglioni A, Donelli A, Maisano F, Jansen JR, Hanania R, Hanlon $\mathrm{P}$, Bovelander J, Alfieri O: Automatic intraaortic balloon pump timing using an intrabeat dicrotic notch prediction algorithm. Ann Thorac Surg 2005, 79:1017-1022; discussion 1022.

18. Benchmark 2 Registry [http://www.datascope.com/ca/pdf/benchmark2 brochure.pdf].

19. Stone GW, Ohman EM, Miller MF, Joseph DL, Christenson JT, Cohen M, Urban PM, Reddy RC, Freedman RJ, Staman KL, Ferguson JJ 3rd: Contemporary utilization and outcomes of intra-aortic balloon counterpulsation in acute myocardial infarction: the benchmark registry. J Am Coll Cardio/ 2003, 
41:1940-1945

20. Urban P, Stauffer JC, Bleed D, Khatchatrian N, Amann W, Bertel O, van den Brand M, Danchin N, Kaufmann U, Meier B, Machecourt J, Pfisterer M: A randomized evaluation of early revascularization to treat shock complicating acute myocardial infarction. The (Swiss) Multicenter Trial of Angioplasty for Shock-(S)MASH. Eur Heart J 1999, 20:1030-1038.

21. Ohman EM, Nanas J, Stomel RJ, Leesar MA, Nielsen DW, O'Dea D, Rogers FJ, Harber D, Hudson MP, Fraulo E, Shaw LK, Lee KL;TACTICS Trial: Thrombolysis and counterpulsation to improve survival in myocardial infarction complicated by hypotension and suspected cardiogenic shock or heart failure: results of the TACTICS Trial. J Thromb Thrombolysis 2005, 19:33-39.

22. O'Rourke MF, Norris RM, Campbell TJ, Chang VP, Sammel NL: Randomized controlled trial of intraaortic balloon counterpulsation in early myocardial infarction with acute heart failure. Am J Cardiol 1981, 47:815-820.

23. Flaherty JT, Becker LC, Weiss JL, Brinker JA, Bulkley BH, Gerstenblith G, Kallman $\mathrm{CH}$, Weisfeldt ML: Results of a randomized prospective trial of intraaortic balloon counterpulsation and intravenous nitroglycerin in patients with acute myocardial infarction. J Am Coll Cardiol 1985, 6:434-446.

24. Alonso DR, Scheidt S, Post M, Killip T: Pathophysiology of cardiogenic shock. Quantification of myocardial necrosis, clinical, pathologic and electrocardiographic correlations. Circulation 1973, 48:588-596.

25. Kovack PJ, Rasak MA, Bates ER, Ohman EM, Stomel RJ: Thrombolysis plus aortic counterpulsation: improved survival in patients who present to community hospitals with cardiogenic shock. J Am Coll Cardiol 1997, 29:1454-1458.

26. Anderson RD, Ohman EM, Holmes DR Jr., Col I, Stebbins AL, Bates ER, Stomel RJ, Granger CB, Topol EJ, Califf RM: Use of intraaortic balloon counterpulsation in patients presenting with cardiogenic shock: observations from the GUSTO-I Study. Global Utilization of Streptokinase and TPA for Occluded Coronary Arteries. J Am Coll Cardiol 1997, 30:708-715.

27. Sanborn TA, Sleeper LA, Bates ER, Jacobs AK, Boland J, French JK, Dens J Dzavik V, Palmeri ST, Webb JG, Goldberger M, Hochman JS: Impact of thrombolysis, intra-aortic balloon pump counterpulsation, and their combination in cardiogenic shock complicating acute myocardial infarction: a report from the SHOCK Trial Registry. SHould we emergently revascularize Occluded Coronaries for cardiogenic shock? J Am Coll Cardiol 2000, 36 (3 Suppl A):1123-1129.

28. Barron HV, Every NR, Parsons LS, Angeja B, Goldberg RJ, Gore JM, Chou TM: The use of intra-aortic balloon counterpulsation in patients with cardiogenic shock complicating acute myocardial infarction: data from the National Registry of Myocardial Infarction 2. Am Heart J 2001 141:933-939.

29. Sjauw KD, Engstrom AE, Vis MM, van der Schaaf RJ, Baan J Jr., Koch KT, de Winter RJ, Piek JJ, Tijssen JG, Henriques JP: A systematic review and metaanalysis of intra-aortic balloon pump therapy in ST-elevation myocardial infarction: should we change the guidelines? Eur Heart J 2009, 30:459-468

30. Prondzinsky R, Lemm H, Swyter M, Wegener N, Unverzagt S, Carter JM, Russ M, Schlitt A, Buerke U, Christoph A, Schmidt H, Winkler M, Thiery J, Werdan K, Buerke M: Intra-aortic balloon counterpulsation in patients with acute myocardial infarction complicated by cardiogenic shock: The prospective, randomized IABP SHOCK Trial for attenuation of multiorgan dysfunction syndrome*. Crit Care Med 2010, 38:152-160

31. Anderson JL, Adams CD, Antman EM, Bridges CR, Califf RM, Casey DE Jr. Chavey WE 2nd, Fesmire FM, Hochman JS, Levin TN, Lincoff AM, Peterson ED, Theroux P, Wenger NK, Wright RS, Smith SC Jr., Jacobs AK, Halperin JL, Hunt SA, Krumholz HM, Kushner FG, Lytle BW, Nishimura R, Ornato JP, Page RL, Riegel B; American College of Cardiology; American Heart Association Task Force on Practice Guidelines (Writing Committee to Revise the 2002 Guidelines for the Management of Patients With Unstable Angina/Non STElevation Myocardial Infarction); American College of Emergency Physicians; Society for Cardiovascular Angiography and Interventions; Society of Thoracic Surgeons; American Association of Cardiovascular and Pulmonary Rehabilitation; Society for Academic Emergency Medicine: ACC/AHA 2007 guidelines for the management of patients with unstable angina/non ST-elevation myocardial infarction: a report of the American College of Cardiology/American Heart Association Task Force on Practice Guidelines (Writing Committee to Revise the 2002 Guidelines for the Management of Patients With Unstable Angina/Non ST-Elevation Myocardial Infarction): developed in collaboration with the American College of Emergency Physicians, the Society for Cardiovascular Angiography and Interventions, and the Society of Thoracic Surgeons: endorsed by the American
Association of Cardiovascular and Pulmonary Rehabilitation and the Society for Academic Emergency Medicine. Circulation 2007, 116:e148-304.

32. Hill JD, O'Brien TG, Murray JJ, Dontigny L, Bramson ML, Osborn JJ, Gerbode F: Prolonged extracorporeal oxygenation for acute post-traumatic respiratory failure (shock-lung syndrome). Use of the Bramson membrane lung. N Engl J Med 1972, 286:629-634.

33. Extracorporeal Life Support Organization (ELSO): ECLS Registry Report, International Summary. Ann Arbor, MI: ELSO; July 2009.

34. Kinsella JP, Gerstmann DR, Rosenberg AA: The effect of extracorporeal membrane oxygenation on coronary perfusion and regional blood flow distribution. Pediatr Res 1992, 31:80-84

35. Koenig PR, Ralston MA, Kimball TR, Meyer RA, Daniels SR, Schwartz DC Balloon atrial septostomy for left ventricular decompression in patients receiving extracorporeal membrane oxygenation for myocardial failure. J Pediatr 1993, 122:595-99.

36. Aiyagari RM, Rocchini AP, Remenapp RT, Graziano JN: Decompression of the left atrium during extracorporeal membrane oxygenation using a transseptal cannula incorporated into the circuit. Crit Care Med 2006 34:2603-2606

37. Haynes S, Kerber RE, Johnson FL, Lynch WR, Divekar A: Left heart decompression by atrial stenting during extracorporeal membrane oxygenation. Int J Artif Organs 2009, 32:240-242.

38. Combes A, Leprince P, Luyt CE, Bonnet N, Trouillet JL, Leger P, Pavie A, Chastre $\mathrm{J}$ : Outcomes and long-term quality-of-life of patients supported by extracorporeal membrane oxygenation for refractory cardiogenic shock. Crit Care Med 2008, 36:1404-1411.

39. Formica F, Avalli L, Martino A, Maggioni E, Muratore M, Ferro O, Pesenti A, Paolini G: Extracorporeal membrane oxygenation with a polymethylpentene oxygenator (Quadrox D). The experience of a single Italian centre in adult patients with refractory cardiogenic shock. ASAIO J 2008, 54:89-94.

40. Smedira NG, Moazami N, Golding CM, McCarthy PM, Apperson-Hansen C, Blackstone EH, Cosgrove DM 3rd: Clinical experience with 202 adults receiving extracorporeal membrane oxygenation for cardiac failure: survival at five years. J Thorac Cardiovasc Surg 2001, 122:92-102.

41. Bakhtiary F, Keller H, Dogan S, Dzemali O, Oezaslan F, Meininger D, Ackermann H, Zwissler B, Kleine P, Moritz A: Venoarterial extracorporeal membrane oxygenation for treatment of cardiogenic shock: clinical experiences in 45 adult patients. J Thorac Cardiovasc Surg 2008, 135:382-388

42. Golding LA, Crouch RD, Stewart RW, Novoa R, Lytle BW, McCarthy PM, Taylor PC, Loop FD, Cosgrove DM 3rd: Postcardiotomy centrifugal mechanical ventricular support. Ann Thorac Surg 1992, 54:1059-1063; discussion 1063-1054.

43. Muehrcke DD, McCarthy PM, Stewart RW, Foster RC, Ogella DA, Borsh JA, Cosgrove DM 3rd: Extracorporeal membrane oxygenation for postcardiotomy cardiogenic shock. Ann Thorac Surg 1996, 61:684-691.

44. Magovern GJ Jr., Simpson KA: Extracorporeal membrane oxygenation for adult cardiac support: the Allegheny experience. Ann Thorac Surg 1999, 68:655-661.

45. Wernovsky G, Wypij D, Jonas RA, Mayer JE Jr., Hanley FL, Hickey PR, Walsh AZ, Chang AC, Castañeda AR, Newburger JW, Wessel DL: Postoperative course and hemodynamic profile after the arterial switch operation in neonates and infants. A comparison of low-flow cardiopulmonary bypass and circulatory arrest. Circulation 1995, 92:2226-2235.

46. Ko WJ, Lin CY, Chen RJ, Wang SS, Lin FY, Chen YS: Extracorporeal membrane oxygenation support for adult postcardiotomy cardiogenic shock. Ann Thorac Surg 2002, 73:538-545.

47. Santise G, Sciacca S, D'Ancona G, Pilato M: Circulatory support system as a bridge to decision in patients with refractory acute cardiogenic shock: is there a space for extracorporeal membrane oxygenation? J Thorac Cardiovasc Surg 2008, 135:717; author reply 717-718.

48. Wagner K, Sangolt GK, Risnes I, Karlsen HM, Nilsen JE, Strand T, Stenseth LB, Svennevig JL: Transportation of critically ill patients on extracorporeal membrane oxygenation. Perfusion 2008, 23:101-106.

49. Huang SC, Chen YS, Chi NH, Hsu J, Wang CH, Yu HY, Chou NK, Ko WJ, Wang SS, Lin FY: Out-of-center extracorporeal membrane oxygenation for adult cardiogenic shock patients. Artif Organs 2006, 30:24-28.

50. DeBakey ME: Left ventricular bypass pump for cardiac assistance. Clinical experience. Am J Cardiol 1971, 27:3-11.

51. Pagani FD: Continuous-flow rotary left ventricular assist devices with "3rd 
generation" design. Semin Thorac Cardiovasc Surg 2008, 20:255-263.

52. Thiele H, Sick P, Boudriot E, Diederich KW, Hambrecht R, Niebauer J, Schuler G: Randomized comparison of intra-aortic balloon support with a percutaneous left ventricular assist device in patients with revascularized acute myocardial infarction complicated by cardiogenic shock. Eur Heart $J$ 2005, 26:1276-1283

53. Burkhoff D, Cohen H, Brunckhorst C, O'Neill WW: TandemHeart Investigators Group: A randomized multicenter clinical study to evaluate the safety and efficacy of the TandemHeart percutaneous ventricular assist device versus conventional therapy with intraaortic balloon pumping for treatment of cardiogenic shock. Am Heart J 2006, 152:469.e1-8.

54. Seyfarth M, Sibbing D, Bauer I, Frohlich G, Bott-Flugel L, Byrne R, Dirschinger J, Kastrati A, Schomig A: A randomized clinical trial to evaluate the safety and efficacy of a percutaneous left ventricular assist device versus intra-aortic balloon pumping for treatment of cardiogenic shock caused by myocardial infarction. J Am Coll Cardiol 2008, 52:1584-1588.

55. Cheng JM, den Uil CA, Hoeks SE, van der Ent M, Jewbali LS, van Domburg RT, Serruys PW: Percutaneous left ventricular assist devices vs. intra-aortic balloon pump counterpulsation for treatment of cardiogenic shock: a meta-analysis of controlled trials. Eur Heart J 2009, 30:2102-2108.

56. Prutkin JM, Strote JA, Stout KK: Percutaneous right ventricular assist device as support for cardiogenic shock due to right ventricular infarction. J Invasive Cardiol 2008, 20:E215-216.

57. Kiernan MS, Krishnamurthy B, Kapur NK: Percutaneous right ventricular assist via the internal jugular vein in cardiogenic shock complicating an acute inferior myocardial infarction. J Invasive Cardiol 2010, 22:E23-26.

58. Rajagopal V, Steahr G, Wilmer Cl, Raval NY: A novel percutaneous mechanical biventricular bridge to recovery in severe cardiac allograft rejection. J Heart Lung Transplant 2010, 29:93-95.

59. Gregoric ID, Jacob LP, La Francesca S, Bruckner BA, Cohn WE, Loyalka P, Kar B, Frazier OH: The TandemHeart as a bridge to a long-term axial-flow left ventricular assist device (bridge to bridge). Tex Heart Inst J 2008, 35:125-129.

60. Samoukovic G, Rosu C, Giannetti N, Cecere R: The Impella LP 5.0 as a bridge to long-term circulatory support. Interact Cardiovasc Thorac Surg 2009, 8:682-683.

61. John R, Liao K, Lietz K, Kamdar F, Colvin-Adams M, Boyle A, Miller L, Joyce L:
Experience with the Levitronix CentriMag circulatory support system as a bridge to decision in patients with refractory acute cardiogenic shock and multisystem organ failure. J Thorac Cardiovasc Surg 2007, 134:351-358.

62. Rose EA, Gelijns AC, Moskowitz AJ, Heitjan DF, Stevenson LW, Dembitsky W, Long JW, Ascheim DD, Tierney AR, Levitan RG, Watson JT, Meier P, Ronan NS, Shapiro PA, Lazar RM, Miller LW, Gupta L, Frazier OH, Desvigne-Nickens P, Oz $M C$, Poirier VL; Randomized Evaluation of Mechanical Assistance for the Treatment of Congestive Heart Failure (REMATCH) Study Group: Long-term mechanical left ventricular assistance for end-stage heart failure. $N$ Engl 」 Med 2001, 345:1435-1443.

63. Rogers JG, Butler J, Lansman SL, Gass A, Portner PM, Pasque MK, Pierson RN 3rd: Chronic mechanical circulatory support for inotrope-dependent heart failure patients who are not transplant candidates: results of the INTrEPID Trial. J Am Coll Cardiol 2007, 50:741-747.

64. Slaughter MS, Rogers JG, Milano CA, Russell SD, Conte JV, Feldman D, Sun B, Tatooles AJ, Delgado RM 3rd, Long JW, Wozniak TC, Ghumman W, Farrar DJ, Frazier OH; HeartMate II Investigators: Advanced heart failure treated with continuous-flow left ventricular assist device. N Engl J Med 2009, 361:2241-2251.

65. Morgan JA, John R, Rao V, Weinberg AD, Lee BJ, Mazzeo PA, Flannery MR, Chen JM, Oz MC, Naka Y: Bridging to transplant with the HeartMate left ventricular assist device: The Columbia Presbyterian 12-year experience. J Thorac Cardiovasc Surg 2004, 127:1309-1316.

66. Vlasselaers D, Desmet M, Desmet L, Meyns B, Dens J: Ventricular unloading with a miniature axial flow pump in combination with extracorporeal membrane oxygenation. Intensive Care Med 2006, 32:329-333.

67. Crow S, Fischer AC, Schears RM: Extracorporeal life support: utilization, cost, controversy, and ethics of trying to save lives. Semin Cardiothorac Vasc Anesth 2009, 13:183-191.

doi:10.1186/cc9229

Cite this article as: Cove M, MacLaren G: Clinical review: mechanical circulatory support for cardiogenic shock complicating acute myocardial infarction. Critical Care 2010, 14:235. 